\title{
Metastatic Malignant Neoplasm in the Vagina
}

National Cancer Institute

\section{Source}

National Cancer Institute. Metastatic Malignant Neoplasm in the Vagina. NCI Thesaurus.

Code C6333.

A malignant neoplasm that has spread to the vagina from another anatomic site. 